\title{
Real law of virtual worlds: russian approach to regulating contractual relations between a player and an operator of multiplayer online game
}

\author{
Dmitry Turitsyn* \\ Head of the Civil Legal Researches Lab., the History, Economics and Law Research Institute, \\ Moscow, Russian Federation
}

\begin{abstract}
The widespread dissemination of Massively Multiplayer Online (MMO) games causes new problems not only in the technical field, but also in the field of law. A number of countries have successfully implemented provisions in their legislation governing the legal relationship between players and distributors of online games. However, most states have left this question unresolved. Based on the real cases, this article examines the judicial practice of resolving disputes between players and operators of MMO games in the Russian Federation. The author shows a real picture of the current state of contract law governing relations in the field of the gaming industry and the position of courts in this matter. It substantiated the conclusion on the duality of approaches to solving the question of the nature of contractual relations depending on the subject going to court in Russia. It shows the imperfection of Russian civil law in this area.
\end{abstract}

\section{Introduction}

In a modern information society, legal relations arise between people not only in the real world - in relation to material objects, but also in relation to intangible virtual objects in digital spaces. Among such objects of undoubted interest, in our opinion, is the sphere of virtual multiplayer game worlds or MMORPG. Despite the fact that such worlds are only an entertainment tool (game), the relations arising between the participants of such games (players) and the operators of the game (distributor), mediate or even directly represent contractual civil legal relations. Relationships regarding digital objects of the virtual world can arise both inside the virtual world and outside it. Their subjects can be players, copyright holders, users, etc.

First of all, it should be noted that MMO ("massively multiplayer online") is a multiplayer online game in which cooperation and communication of a large number of players around the world via the Internet is assumed. In most MMO games, you can find elements of the virtual economy, which is the exchange and trade between players of in-game items and ingame currency [1]. Consequently, in such worlds civil circulation is also mediated, including through contractual regulation.

${ }^{*}$ Corresponding author: turitsyn.d@ hotmail.com 
British researcher Barker Kim distinguishes two types of virtual worlds - scripted environments and unscripted environments. In the case of the first worlds, the player is limited in freedom. Its activity in the virtual world involves the passage of a scenario, upon completion of certain tasks of which the character develops and the game progress is promoted. World of Warcraft is a prime example of such a game. In contrast, unscripted environments virtual worlds provide players with complete freedom of action. Their activities in the virtual world are not limited by the scenario. Instead, players can create their own scenarios in such a world. The game 'Second Life' is a good example [2]. Access to such games is carried out by connecting the user (player) with an account to the server of the game holder (distributor or operator) via the Internet. In turn, a user account in such a virtual world acts as a kind of passport and, at the same time, as a tool for playing activities in the virtual world.

\section{Methodology}

The research methodology is made up by sociolegal method, method of legal statics, method of legal cybernetics and method of legal forecasting.

\section{Results}

During the research it is analyzed the Russian judicial practice of regulating contractual relations between a Player and an Operator of MMO-games. On the basis of this analysis, it is also substantiated the conclusions and proposed the ways of solving the existing collisions.

\section{Content}

In this regard, let's consider the Determination of the Moscow City Court dated November 16, 2015 No. 4g/6-11858/15 [3], in which the court, refusing to transfer the plaintiff's cassation appeal against the Decision of the Simonovskiy District Court of Moscow dated April 17, 2015 on the appeal ruling of the Judicial Collegium for Civil Cases of the Moscow City Court dated July 14, 2015, established that the plaintiff, acting in his own interests and in the interests of a minor, filed a lawsuit against 'Gameshok' LLC, 'Qwery' LLC, 'Novoplay' LLC and individual entrepreneur A., demanding to recognize the User Agreement and the Terms of Service for the game 'Light \& Darkness' partially invalid, as well as requirements for a refund, forfeit, compensation for moral damage and a fine for purchased paid services.

Based on the materials of the case, the plaintiff and his minor son, in accordance with the terms of the User Agreement, registered two accounts to access the free browser-based MMO game 'Light \& Darkness'. To access this online game, player can use the social networks 'Vkontakte', 'My World', 'Odnoklassniki'. Despite the fact that the game itself is free, clauses 4.2 and 4.3 of the User Agreement provided for the possibility of obtaining additional paid services and unlimited access to the game by transferring funds through additional computer programs (services). In the period from April 2013 to November 2013, the plaintiff purchased additional paid services on his account and the account of his son. On November 24, 2013, without prior notice, all additional paid services were disabled on both accounts, which caused losses. The reason for the shutdown of additional account services was the establishment of a balance of interests of the players in the above-mentioned MMO game, which was provided for in clauses 1.6, 7.11 of the User Agreement and the terms of the game. It should be noted that when registering an account, the user assumes the obligation to read this agreement, after which he confirms his consent with him by putting a mark in the clickwrap form "I agree". 
According to clause 1.6 of the above agreement, the administration had the right to make changes and adjustments to any constituent components of the services without special notice to the user. In accordance with clause 7.5 , the receipt of additional paid services did not release users from compliance with the User Agreement, the Project Rules and the application of any measures stipulated by the User Agreement in relation to them, including full or partial refusal of the Administration to provide additional paid services to the user. At the same time, clause 7.11 of the User Agreement established that the moment the Administration provides an additional paid service is the moment when the Administration debits funds from the user's personal account for paying for this additional paid service and receiving (using) the additional paid service by the user. From this moment, the additional paid service is considered to be provided by the Administration to the user in full, on time and with proper quality.

The court of first instance established that on November 18, 2013 'Novoplay' LLC, being the owner of the exclusive rights to the "Light \& Darkness" game, transferred this exclusive right to 'Qwerty' LLC, which concluded the software product distribution agreement No. 130813-1 from November 19, 2013 with 'Gameshock' LLC, thereby transferring to the latter the rights of the Project Administrator. Thus, considering the provisions of the User Agreement, the defendant was entitled to disable paid services, including those listed by the plaintiff, in order to maintain the balance of users in the free MMO game 'Light \& Darkness'. Thus, in the court's opinion, the decision to block the plaintiff's accounts did not violate the current Civil Code of the Russian Federation (CCRF), the Law 'On Protection of Consumer Rights', and other legislative acts. Consequently, the defendant had the right to disable the paid services listed by the plaintiff. The court also noted that the User Agreement concluded between the parties does not contain a condition on payment of remuneration to the user of the game, participation in the game is free, and the agreement is concluded indefinitely.

It seems interesting to resolve the issue of the substantive law applicable to this dispute. The first instance court applied the provision of paragraph 1 of Art. 1062 of the Civil Code of the Russian Federation (Requirements related to the organization of games and bets and participation in them), according to which 'the claims of citizens and legal entities related to the organization of games and bets or with participation in them are not subject to judicial protection, with the exception of claims participation in games or bets under the influence of deception, violence, threat or malicious agreement between their representative and the organizer of the games or bets' [4]. Thus, the court recognized the relationship arising between the user and the distributor of the online game in relation to the account, as well as the provisions of the User Agreement as an element of the organization of games.

In the appeal, the plaintiff pointed to the unreasonableness of the application of the provisions of Article 1062 of the CCRF instead of Art. 1064 of the CCRF (General provisions for liability for harm), however, the court noted that, according to clause 2 of the User Agreement, the user uses the game at its own risk, the game is provided on an 'as is' basis, that is, the user is not guaranteed that the game, as well as the capabilities and services provided within the game and the services will function smoothly, continuously, without errors. The court of the cassation instance refused to initiate the process in the cassation instance.

Thus, we see that a game account for accessing an MMO game was considered by the Russian court precisely as a means of individualizing a user in the virtual world. The account linked to the account was considered as a single whole with the account itself, and the relationship between users and the project administration, for the most part, was regulated by a kind of agreement - the User Agreement. However, all this, according to the court, was an element of the organization of gambling, therefore, the dispute on these grounds could not be considered in court. 
We can observe a completely different state of affairs in American courts. Thus, from the case file Bragg v. Linden Research, Inc., considered by the US District Court for the Eastern District of Pennsylvania in 2006-2007, it follows that plaintiff Bragg took legal action against Linden Research Inc., the operator of Second Life, a paid multiplayer online game and founder Rosedahl, on the protection of their virtual property and access to the virtual world. This case has been examined in detail by various researchers (for example, De Zwart M. [5] or Cabasso A. [6]). Considering their position, we can summarize the following: the case of Bragg v. Linden Research, Inc. showed that agreements with users in the USA do not have absolute superiority in establishing legal relations between the game operator and the player. Also, this precedent made it possible to define user agreements as an accession agreement, which is an important legal event. It is especially important that the court did decide to proceed with the claim for the protection of rights in the online game on the issue of virtual property. As Dougherty C. noted, this case raises a fairly large layer of legal issues that are important for the regulation of legal relations in virtual worlds. Thus, this process marked the beginning of the protection of virtual property rights [7].

Thus, we see that the Russian courts most often refuse to examine in detail cases and actually study the essence of such disputes, preferring to confine themselves to a reference to Art. 1062 of the CCRF and refuse to protect the rights of players, citing the impossibility of a court to consider disputes related to games. The paid services and in-game objects themselves are considered by the courts as part of the program code, an additional incomplete license to use part of the computer program, and the relations arising between the players and the game administration are regulated by a license agreement.

In our opinion, precisely because of the possibility of using various legal norms, today in Russian courts there is a deep contradictory of approaches to determining the legal status of in-game objects and the relations that arise between users of MMO games and owners (operators) of such games, which directly depends on the status of the subject of appeal to the court instance. In particular, it becomes particularly obvious in cases where this area suddenly affects the interests of the state and the budget.

Particular interest, in this regard, is the case initiated by 'Mail.RuGames' LLC (Company) regarding the invalidation of the Decision of the Federal Tax Service Inspectorate No. 14 in Moscow (FTSI) dated December 27, 2013 No. 5006 'On Refusal to Hold Accountable for a Tax Crime'.

Being the copyright holder of a number of interactive computers MMO games, 'Mail.RuGames' LLC organizes their operating. The main source of regulation of relations between players and the administration is a License Agreement, the conclusion of which is through the acceptance of public offers placed by the Company on the Internet on its websites. Such a license agreement also includes the Game Rules, previously referred to as the user agreement (Rules). In accordance with these Rules, users who, in the prescribed manner, have registered an account, are given the opportunity to access an online game using the F2P system ('Free-To-Play'). It also provides the possibility of obtaining additional benefits and privileges in the game, which serve to facilitate the gameplay. It should be noted that such paid services often provide players with the opportunity to receive certain in-game items or in-game currency, which is required to purchase these same items.

The court of first instance, after examining the statements and arguments of the parties, established that the 'Mail.RuGames' LLC on April 22, 2013 was submitted an initial VAT tax return for the 1st quarter of 2013, which reflects the amount of tax payable to the budget in the amount of 212582165 rubles (approximately 6723028 dollars at the rate of 1 dollar $=31.62$ rubles).

'Mail.RuGames' LLC indicated that, by virtue of art. 1261 of the CCRF, an online game is a computer program [8], therefore, according to clause 26 of p. 2 of art. 149 of the Tax Code of the Russian Federation (TCRF), income from its sale is not subject to taxation. Using 
this provision, in the indicated quarter, the Company granted the right to use the client part of MMO games, and also organized the game process. According to 'Mail.RuGames' LLC, the additional functionality of the games (AFG), which is transferred to individuals for a fee, is an object of intellectual property and an object of exclusive rights, i.e. part of a computer program. Therefore, the conclusion of the inspection that such activities under Licensing Agreements is the provision of services is unfounded.

The FTSI, on the contrary, insisted that operations involving the sale of extended services to individuals while participating in the game in the form of a reimbursable transfer of rights to use AFG cannot be considered part of the provision of a part of the computer program. During the trial, the tax authority indicated that the right to use AFG was transferred to individuals on a reimbursable basis, as an independent result of intellectual activity, separately from the right to use the client part of the game, as a computer program as a whole. Nevertheless, from the contents of the recall and written explanations of the FTSI, it follows that AFGs are an integral element of the client part of the game, which is transmitted to the user free of charge when transferring rights to use this part of the game.

Understanding this difficult situation, the court pointed out that, in fact, operations to provide AFG are nothing more than the provision of services for the organization of the game process. The court further explains that the game, acting as a computer program, is a complex object, the result of intellectual activity, a single software product that includes the Client Part (the right to use which, according to the terms of the License Agreements, is transferred to the licensee free of charge at the time of 'Download'), as well as the Server Part (which is used by the operator to carry out its functions for organizing the game process). According to clause 1.9 of the License Agreement, the client part of the game is the software necessary for the participation of individuals in the game, including access to the AFG. Such software is provided to the user at a time after downloading and joining the license agreement. To get access to the DFI, you do not need to download and install additional software.

The court concluded that there was no other form of transfer of the right to use the AFG. Therefore, taking into account the fact that a player can use the AGF only after crediting funds to its account for the purchase of units of rights, the true will of 'Mail.RuGames' LLC and clients, when concluding a License Agreement, is aimed at providing such clients with services for organizing the game process on the game resource of Society. The list of such services is established clause 9 of License Agreement. The legal status of in-game items is established by clause 9.2, according to which such objects are intangible and can only be used inside the game during the game process. The court also noted that the confirmation of the emergence of relations between the Company and users for the Term of Services is also confirmed by the wording of rights and obligations.

Thus, the court considers that in reality the contracts concluded by 'Mail.RuGames' LLC with users are mixed: for the gratuitous transfer of rights to use the results of intellectual activity, as well as for rendering game organization services on a reimbursable basis.

The Society tried to prove that the player, acquiring AFG, uses the extended version of the game. Thus, easy access is something similar to the trial version of the program. However, the court did not agree with this position, noting that the trial version of the computer program is not limited, but contains the same functionality as the full version of the computer program. After the trial period expires, the program continues to work, but with limited functionality. A trial version can be provided to the user for the test. Thus, we cannot say that the usage of AFG makes the program complete. At the same time, the right to use AFG is transferred to the licensee free of charge at one time - together with the right to use the Client part of the game. The elements of the AFG are an integral part of the game. They represent certain teams and codes that are already in the game along with graphic images that are initially provided to the player as part of a computer program for free. All users playing for free or paid are in a single gaming space. AFG is available to all users, regardless of payment. Without 
exception, players can see such elements on the virtual personifications of other players who have an AFG, which they could get, including by winning or stealing from another player.

In the course of the proceedings, the court also came to the conclusion that the use of paid services in the framework of the game carries all the signs of c. 1 of art. 779 of the CCRF, in accordance with which, under a contract for the provision of services, the contractor agrees to provide the services on the instructions of the customer (perform certain actions or carry out certain activities), and the customer agrees to pay for these services, which is confirmed by the provisions of clause 9 of the License Agreement (section on AFG). In other words, in fact, the user in the process of acquiring an AFG purchases units of change of rights for the subsequent acquisition of certain privileges in the game, which facilitate the game process and increase the ability of the game character on the user's account both on a permanent and temporary basis, which, of course, can be characterized precisely as a service delivery activity.

It is noteworthy that in order to give an opinion on the legal nature of model License Agreements, leading experts of the Institute of State and Law of the Russian Academy of Sciences, Doctor of Law T. E. Abova and Ph.D. E. N. Vasilyev. Answering the questions posed, scientists noted that, despite the fact that the agreement is referred to as a license agreement, and its parties - the licensor and licensee, the rights to use the game are not licensed, with the exception of the terms on the right to use the client part of the game, which implies reproduction by recording in the memory of the computer of the licensee of the game as a computer program, and therefore - the granting of permission (license) for the licensee to perform this action. Thus, such an agreement can be qualified as a mixed one - containing elements of a gratuitous license agreement, in one part, and also a reimbursable contract for the provision of services - in another part.

Thus, we see that the court directly indicated that the relations arising between the user of the online game and the operator of such online game are mixed, that is, they contain elements both a license agreement, and a service agreement. Therefore, such relations are recognized by civil law, which means that their protection is possible in the courts of general and arbitration jurisdiction.

As regards the subject of the case itself, the court partially satisfied the claim of 'Mail.ru Games' LLC, however, it indicated the fact of abuse of its right as a taxpayer. The tax amount was reduced to $184,114,971$ rubles (approximately 5,573,000 dollars). Also, a state duty in the amount of 2,000 rubles was collected from the FTSI in favor of the Company. At the same time, the rest of the requirements were refused [9]. Disagreeing with the decision of the court of first instance, 'Mail.RuGames' LLC appealed to the Ninth Arbitration Court of Appeal, but the court of appeal rejected the complaint, leaving the decision of the court of first instance unchanged [10]. Cassation proceedings continued in the Arbitration Court of the Moscow District, which dismissed the appeal of the 'Mail.RuGames' LLC [11]. The point in this dispute was set by the Supreme Court of the Russian Federation (SCRF), which, upon refusing the cassation appeal of 'Mail.RuGames' LLC, noted in its determination that the lower courts had concluded that there were no grounds for re-qualifying relations regarding the use of AGF provided to players for a fee under a license agreement, since the terms of the disputed agreement establish the procedure for determining the price of services received in the form of equipping the game character with additional privileges and payment with cost of rights to use additional functionality made in cash to the value of a certain number of rights units [12].

\section{Conclusions}

Thus, at present, the problem of regulating relations between users (players) and copyright holders for MMO games and its operator in the Russian Federation is fundamentally 
conflicting, collision. Although there are rules that allow you to regulate these legal relations in modern Russian legislation, they are applied selectively in judicial practice. AFG is considered by the courts both as part of the computer program code provided to the player under a license agreement (an additional incomplete license to use part of the computer program) and as a paid service provided to the user by the game copyright holder under a paid services agreement.

Summarizing our position, we note, that the recognition by the Supreme Court of the Russian Federation in the framework of case No. A40-56211/2014 of the rules of the game as a mixed agreement (license agreement and service agreement) directly indicates that between the players (users of MMO -game) and the copyright holder (distributor of the game), complex legal relations arise, therefore, these legal relations are regulated by civil law through the provisions of both of these agreements. It follows that one of the participants in such an agreement is a player, from the position of the SCRF, within the framework of the contractual relationship between they and the copyright holder, is considered not only as a licensee, but also as a consumer of services in that part of the agreement that relates to the provision of these services. Thus, the refusal with reference to article 1062 of the CCRF in satisfying the claims of players who have applied to the court for the restoration of violated rights after acquiring the AFG is illegal and unreasonable It is impossible to apply the provisions of civil law to a single contract with different interpretations depending on the situation and status of entities applying for the protection of their rights. The rights of each party to the contractual relationship must be protected. The protection of the rights of one side while ignoring the status and rights of the other side is unacceptable. The recognition of users exclusively by players only because of the fact of their participation in the game process seems to us to be an erroneous qualification of the subject of contractual relations.

In other words, if the SCRF recognized such contractual relations as complex, including those aimed at providing services, players should automatically be recognized, in addition to licensees, as consumers of services. Their rights in that part of the contract that regulates the provision of services should be protected by the court as the rights of the consumer of services. Otherwise, the SCRF must recognize that such contractual relations are not complex and do not include elements of a service contract. However, in such a situation, the collection of tax on the provision of AFG to players from the owners of MMO games is unacceptable and unlawful.

In our opinion, there are two ways to correct these shortcomings. The first involves the adjustment of the norms of the Civil Code of the Russian Federation, the introduction of special provisions relating to multi-user online games. This method is more effective, but it requires a lot of labor and a detailed study of the relevant standards, their thoughtful coordination with the existing contractual institutions. The second method is judicial. The Supreme Court of the Russian Federation needs to decide on the issue of enforcement of specific provisions of the Civil Code of the Russian Federation to these legal relations and to draw up these conclusions in the form of a Resolution of the Plenum of the Supreme Court of the Russian Federation. This method seems to us more flexible.

\section{References}

1. R. E. Wells III, What Is an MMO? J. of Phys.: Conference Series, (2019) Available from: https://www.lifewire.com/what-is-an-mmo-4687003/

2. K. Barker, MMORPGing - The Legalities of Game Play, Eur. J. Law \& Tech. 3(1), (2012) Available from: http://ejlt.org/article/view/119/195/

3. Determination of the Moscow City Court dated November 16, 2015, No 4g/6-11858/15

4. The Civil Code of the Russian Federation (Part II) 
5. M. De Zwart, Contractual Communities: Effective Governance of Virtual Worlds, UMSW, Law J. 33(2), 605 (2010)

6. A. Cabasso, Piercing Pennoyer with the Sword of a Thousand Truths: Jurisdictional Issues in the Virtual World, Fordham Int. Prop. Media and Entertainment Law J. 22(2), 384-423 (2012)

7. C. Dougherty, Bragg v. Linden: Virtual Property Right Litigation, E-Commerce Law \& Policy 9, 7 (2007).

8. The Civil Code of the Russian Federation (Part II)

9. Decision of the Arbitration Court of the city of Moscow April 08, 2015 in case No. A40 56211/14-90-70

10. Decree of the Ninth Arbitration Court of Appeal June 26, 2015 No. 09AP-22635/2015 in case No. A40-56211/14

11. Decree of the Arbitration Court of the Moscow District October 12, 2015 No. F05$13554 / 2015$ in case No. A40-56211/14

12. Determination of the Supreme Court of the Russian Federation February 3, 2016 No. 305-KG15-18998 in case No. A40-56211/2014 